\title{
ORIGINAL
}

\section{Preoperative insulin secretion ability and pancreatic parenchymal thickness as useful parameters for predicting postoperative insulin secretion in patients undergoing pancreaticoduodenectomy}

\author{
Atsushi Yoshikawa $^{1)}$, Junji Kozawa ${ }^{1)}$, Kohei Okita ${ }^{1)}$, Sho Yoneda ${ }^{1)}$, Yukiyoshi Okauchi ${ }^{1)}$, Sae Uno ${ }^{1)}$, \\ Hiromi Iwahashi ${ }^{1)}$, Tetsuya Ohira ${ }^{2)}$, Daisuke Takiuchi ${ }^{3)}$, Hidetoshi Eguchi ${ }^{3)}$, Yutaka Takeda ${ }^{3)}$, \\ Akihisa Imagawa $^{1)}$ and Iichiro Shimomura ${ }^{1)}$ \\ 1) Department of Metabolic Medicine, Graduate School of Medicine, Osaka University, Suita 565-0871, Japan \\ 2) Public Health, Department of Social and Environmental Medicine, Graduate School of Medicine, Osaka University, Suita 565- \\ 0871, Japan \\ 3) Department of Surgery, Graduate School of Medicine, Osaka University, 2-2 Yamadaoka, Suita 565-0871, Japan
}

\begin{abstract}
Periampullary malignant neoplasms have been increasing in Japan, mainly in response to an increase in the incidences of pancreatic cancer, and glucose intolerance due to deterioration of insulin secretion is an important problem. We investigated preoperative parameters to predict postoperative insulin secretion and the need for insulin therapy in patients undergoing pancreaticoduodenectomy (PD). Thirty-six patients with malignant neoplasms of periampullary lesions were enrolled. Preoperative pancreatic parenchymal thickness was evaluated by computed tomography. Insulin secretion and glucose tolerance were evaluated by a 75-g oral glucose tolerance test and an intravenous glucagon loading test. The relationships between postoperative insulin secretion and preoperative parameters and the cut-off values for predicting the need for postoperative insulin therapy for glycemic control were investigated. Pancreatic parenchymal thickness and other preoperative parameters, including the increment of serum C-peptide ( $\triangle \mathrm{C}$-peptide), fasting plasma C-peptide (F-CPR), insulinogenic index (I.I.) and fasting plasma glucose (FPG), were significantly associated with postoperative insulin secretion. Multiple regression analyses revealed that preoperative $\triangle \mathrm{C}$-peptide or F-CPR was the most significant determinant of postoperative insulin secretion, followed by pancreatic parenchymal thickness. In the receiver operating characteristic curve, the best preoperative cut-off values for predicting the need for postoperative insulin therapy were a $\Delta$ C-peptide of $0.65 \mathrm{ng} / \mathrm{mL}$, a F-CPR of $0.85 \mathrm{ng} / \mathrm{mL}$ and a pancreatic parenchymal thickness of $6.0 \mathrm{~mm}$. Both preoperative insulin secretion and pancreatic parenchymal thickness effectively predict postoperative insulin secretion and identify subjects who need postoperative insulin therapy for glycemic control.
\end{abstract}

Key words: Pancreaticoduodenectomy, Insulin secretion, Glucose tolerance, Pancreatic parenchymal thickness

PERIAMPULLARY malignant neoplasms have been increasing in Japan, mainly in response to an increase in the incidences of pancreatic cancer. The surgical resection rate has also been increasing because of recent advances in surgical techniques. Pancreatic cancer is the fifth leading cause of cancer-related death in

Submitted Oct. 31, 2011; Accepted Jan. 26, 2012 as EJ11-0322

Released online in J-STAGE as advance publication Feb.25, 2012

Correspondence to: Kohei Okita, M.D., Ph.D., Address: Department of Metabolic Medicine, Graduate School of Medicine, Osaka University, 2-2 Yamadaoka, Suita 565-0871, Japan.

E-mail: oki@endmet.med.osaka-u.ac.jp males and the sixth leading cause in females in Japan [1], and pancreaticoduodenectomy (PD) is the main operative procedure, accounting for approximately $60 \%$ of all pancreatic cancer surgery [2]. Among the complications of PD, glucose intolerance is an important problem, and diabetes mellitus develops postoperatively in $20-50 \%$ of patients $[3,4]$. PD involves the surgical reduction of approximately $50 \%$ of the pancreatic parenchymal tissue [5], and insulin secretion usually deteriorates because of a reduction in beta cell mass [5-8]. Glucose tolerance is determined by the balance between insulin secretion and insulin resis- 
tance. After surgery, an impairment of glucose tolerance often occurs, or preexisting diabetes mellitus deteriorates because the reduced beta cell mass fails to sustain sufficient insulin secretion. In humans, glucose levels begin to rise when the beta cell mass is reduced by approximately $50 \%$ [9], and the extent of beta cell loss in patients with overt diabetes has been reported to be $65 \%$ [10].

Postoperative insulin secretion is evaluated by various clinical methods, such as a urinary C-peptide measurement, a 75-g oral glucose tolerance test (75-g OGTT) and an intravenous glucagon test. For patients undergoing pancreatectomy, these tests are can be stressful and time-consuming [11]. Identification of a preoperative parameter to predict postoperative insulin secretion and the need for postoperative insulin therapy as a result of reduced insulin secretion could be useful. To date, however, no such preoperative parameter has been clearly identified. In human islet transplantation, a larger size or weight of the donor pancreas has been associated with a larger number of isolated islets, and pancreatic size or weight was one of the important factors for the success of islet isolation [12-14] suggesting that pancreatic size might directly reflect beta cell mass and insulin secretion. In recent studies, pancreatic volume measured by computed tomography (CT) with three-dimensional imaging has been correlated with glycemic control and insulin secretion $[15,16]$. However, three-dimensional analysis of the pancreas is not common in current clinical practice. In the present study, we analyzed the relationships between various preoperative parameters, including pancreatic thickness (easily measured by CT with two-dimensional imaging $[17,18]$ as a parameter reflecting the total postoperative remnant pancreatic volume, and postoperative insulin secretion to determine which parameter would best predict postoperative insulin secretion. We also analyzed the optimal preoperative cut-off values for identifying subjects requiring postoperative insulin therapy.

\section{Materials and Methods}

\section{Patients}

Thirty-six patients (22 males and 14 females) who had malignant neoplasms of periampullary lesions underwent PD between April 2008 and June 2011 in the Department of Surgery, Osaka University Hospital. The mean age, body mass index (BMI) and HbA1c values of the patients were $62.7 \pm 12.4$ years, $20.8 \pm 2.5$ $\mathrm{kg} / \mathrm{m}^{2}$ and $5.4 \pm 1.0 \%$ (Japan Diabetes Society, JDS), respectively. Twenty-two patients had pancreatic carcinoma; 5 patients had ampullary carcinoma; 3 patients had duodenal carcinoma; 3 patients had bile duct carcinoma; 2 patients had malignant endocrine carcinoma; and 1 patient had carcinoma of the transverse colon. Patients who had intraductal papillary mucinous neoplasm (IPMN) or benign tumors were excluded from this study. Glucose tolerance, insulin secretion and insulin resistance were examined before and after pancreatic surgery. All of the postoperative examinations were conducted when the patients were able to take food orally and no longer required an intravenous drip. After surgery, all patients were treated with diet. If the fasting plasma glucose level was greater than $126 \mathrm{mg} /$ $\mathrm{dL}$ or the plasma glucose level at any other time was greater than $200 \mathrm{mg} / \mathrm{dL}$, treatment with insulin was initiated. Written informed consent was obtained from all participants, and this study was approved by the Ethics Committee of Osaka University.

\section{Methods}

Preoperative pancreatic parenchymal thickness was used as a measure of total postoperative remnant pancreatic volume. The preoperative morphology of the pancreas was examined by CT $[17,18]$. Abdominal CT scans were performed within one month prior to surgery. Pancreatic parenchymal thickness was defined as the width of the entire gland minus the main pancreatic duct (MPD) diameter along the minor axis. The thickness was also measured manually in the region of the pancreas where the maximum MPD diameter was determined at the pancreatic tail side of the neoplasm (Fig. 1) [17].

Glucose tolerance was classified into three previously described categories according to a 75-g OGTT using Japanese criteria (normal type, borderline type and diabetic type) [19]. Patients with $\mathrm{HbA} 1 \mathrm{c} \geq 6.5 \%$ (JDS), a fasting plasma glucose $\geq 126 \mathrm{mg} / \mathrm{dL}$ or hypoglycemic agents were regarded as diabetic when they were not undergoing the 75-g OGTT. Insulin secretion was evaluated by the insulinogenic index (I.I.) and the disposition index (D.I.) of a 75-g OGTT and the increment of serum C-peptide ( $\Delta$ C-peptide) after a $1 \mathrm{mg}$ intravenous injection of glucagon [19-21]. The disposition index (D.I.) was used to measure insulin secretion adjusted for the degree of insulin sensitivity. The I.I. and D.I. were evaluated in 26 patients before PD and in 30 patients after PD. Values of $\Delta \mathrm{C}$-peptide 


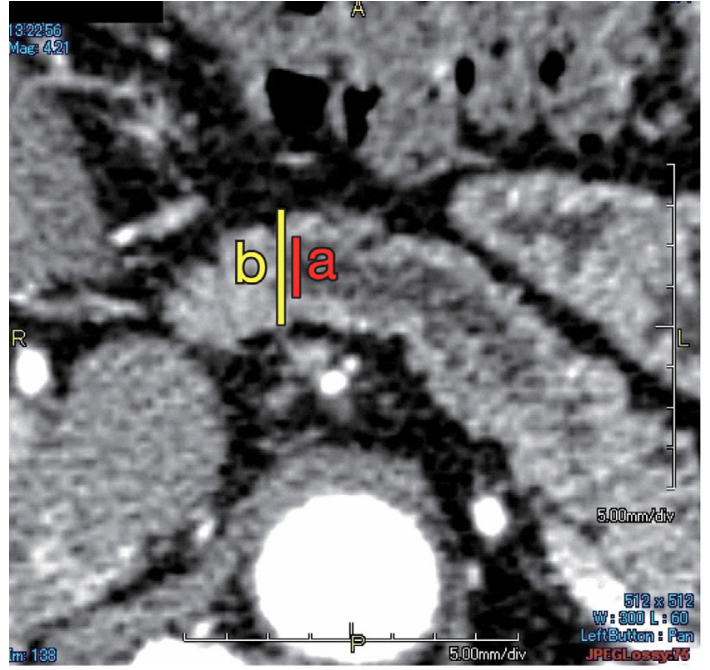

Fig. 1 The method for measuring pancreatic parenchymal thickness. The main pancreatic duct (MPD) diameter was measured manually in the region where the maximum MPD diameter was identified (a). The width of the entire gland in line with the minor axis was measured manually in the region of the pancreas where the maximum MPD diameter was identified (b). The pancreatic parenchymal thickness was defined as (b) minus (a).

were determined in 26 patients before PD and in 32 patients after PD. Patients who could not tolerate the 75 g glucose juice orally as a result of gastrointestinal symptoms or who were fasting and under intravenous drip did not undergo these perioperative tests. The I.I. was defined as the ratio of the increment of insulin to that of plasma glucose at $30 \mathrm{~min}$ after the glucose load ( $\Delta$ serum insulin 0-30 $\mathrm{min} / \Delta$ plasma glucose $0-30$ $\mathrm{min})$. The value of $\Delta \mathrm{C}$-peptide was defined as the difference between the 6 min value of serum C-peptide and its basal value. D.I. was calculated as the product of the insulin secretion $\mathrm{x}$ insulin sensitivity as previously reported [20]. Insulin secretion was calculated using the ratios of total insulin area under the curve (AUC) and total glucose AUC during 0-30 and 0-120 min of the OGTT. Insulin sensitivity was calculated as Matsuda index. The relationships between postoperative I.I., $\Delta$ C-peptide or D.I. and preoperative age, BMI, pancreatic parenchymal thickness, fasting plasma glucose, fasting serum insulin, F-CPR, I.I., D.I. and $\Delta$ $\mathrm{C}$-peptide were investigated. Insulin resistance was also evaluated by the homeostasis model assessment of insulin resistance (HOMA-IR) and the Matsuda index. HOMA-IR was calculated by the following formula: fasting plasma glucose $\left(\mathrm{G}_{0}\right)$ x fasting insulin $\left(\mathrm{I}_{0}\right) / 405$.
The Matsuda index was calculated by the following formula: $10000 /\left(\mathrm{G}_{0} \times \mathrm{I}_{0} \times \mathrm{G}_{120} \times \mathrm{I}_{120}\right)^{1 / 2}$ [22]. We investigated appropriate cut-off values for preoperative parameters, including pancreatic parenchymal thickness, to identify subjects who required postoperative insulin therapy for glycemic control.

\section{Statistical analyses}

Data are presented as the mean \pm standard deviation (S.D.). Pearson's correlation coefficient analysis was used to assess the relationships between the postoperative parameters of insulin secretion (I.I., $\Delta$ C-peptide and D.I.) and the preoperative parameters, as well as the relationship between postoperative plasma glucose level in the 75-g OGTT and pancreatic parenchymal thickness. Multiple regression analyses were conducted to determine the contribution of each preoperative parameter to the postoperative I.I. and $\Delta$ C-peptide. Receiver operating characteristic (ROC) curves were used to determine the appropriate cut-off values for preoperative parameters, including preoperative $\Delta \mathrm{C}$-peptide, fasting plasma C-peptide (F-CPR), fasting plasma glucose (FPG) and pancreatic parenchymal thickness, to identify subjects who needed postoperative insulin therapy. A Wilcoxon signed-ranks test was used to compare I.I., $\Delta$ C-peptide and D.I. values before and after surgery. A P value $<0.05$ was taken to indicate significant difference. All statistical analyses were performed with StatView (Statistical Analysis System Inc., Cary, NC) or the SPSS Statistica software package (version 11.0.1J; SPSS, Chicago, IL).

\section{Results}

Preoperative glucose tolerance of 15 patients was normal, 6 patients were borderline diabetic and 15 patients were diabetic. Nine diabetic patients were treated with diet; 2 diabetic patients were treated with oral hypoglycemic agents; and 4 diabetic patients were treated with insulin. The postoperative glucose tolerance test showed that 14 patients were normal, 13 patients were borderline diabetic and 7 patients were diabetic. Glucose tolerance in 2 patients could not be evaluated because one patient could not drink the $75 \mathrm{~g}$ of glucose juice, and the other patient died two months after the operation. Among the 15 patients whose preoperative glucose tolerance was normal, 9 patients were also normal, but 6 patients regressed to borderline diabetic status after surgery. Among the 15 preoperative 
diabetic patients, 7 patients were also diabetic, but 7 patients were ameliorated to normal or borderline diabetic after surgery. Among 6 preoperative borderline diabetic patients, 2 patients were also borderline diabetic, but 3 patients were ameliorated to normal. Five postoperative diabetic patients were treated with insulin and 2 postoperative diabetic patients were treated with diet. Among the 5 patients who required postoperative insulin therapy, 3 of them had been treated preoperatively with insulin and 2 had been treated preoperatively with oral anti-diabetic drugs.

Preoperative $\Delta \mathrm{C}$-peptide was significantly reduced after surgery $(2.5 \pm 2.3 \mathrm{ng} / \mathrm{mL}$ to $1.2 \pm 1.4 \mathrm{ng} / \mathrm{mL}, p<$ 0.0001 ). Preoperative I.I. was $0.72 \pm 0.77$ and decreased to $0.51 \pm 0.61$ after surgery, but this reduction was not significant $(p=0.86)$. Preoperative D.I. $0-30$ was 1.6 \pm 1.9 and decreased to $1.4 \pm 1.4$ after surgery, but this reduction was not significant ( $p=0.45$ ). Preoperative D.I. $0-120$ was $2.1 \pm 2.2$ and decreased to $1.7 \pm 1.5$ after surgery, but this reduction was not also significant $(p=$
0.78) (Table 1). Postoperative $\Delta \mathrm{C}$-peptide was evaluated $25.4 \pm 12.6$ days after PD, and postoperative I.I. and D.I. were evaluated $30.7 \pm 18.5$ days after PD. The postoperative $\Delta \mathrm{C}$-peptide levels in the five patients who needed insulin therapy for glycemic control after PD were $0,0.1,0.2,0.5$ and $0.5 \mathrm{ng} / \mathrm{mL}$.

The pancreatic parenchymal thickness ranged from 2.3 to $24.7 \mathrm{~mm}$, and the mean thickness was $9.7 \pm 4.9$ $\mathrm{mm}(\mathrm{n}=36)$. The pancreatic parenchymal thicknesses in the five patients who needed postoperative insulin therapy while taking food, with no intravenous drip, were 3.3, 5.0, 5.5, 5.9 and $7.0 \mathrm{~mm}$.

The relationships between postoperative insulin secretion and preoperative clinical parameters are shown in Table 2. There were significant linear relationships between postoperative I.I. and preoperative $\Delta$ C-peptide ( $r=0.82, p<0.0001)$ and pancreatic parenchymal thickness $(\mathrm{r}=0.66, p<0.0001)$ (Fig. 2). There were also significant linear relationships between postoperative $\Delta \mathrm{C}$-peptide and preoperative $\Delta \mathrm{C}$-peptide ( $\mathrm{r}$

Table 1 Preoperative and postoperative clinical parameters of the study subjects

\begin{tabular}{lccc}
\hline & Pre & Post & $p$ value \\
\hline Fasting plasma glucose $(\mathrm{mg} / \mathrm{dL})$ & $98.5 \pm 17.0$ & $104.1 \pm 23.7$ & N.S. \\
Fasting serum insulin $(\mu \mathrm{U} / \mathrm{mL})$ & $4.9 \pm 2.2$ & $4.2 \pm 2.9$ & N.S. \\
Fasting serum C-peptide $(\mathrm{ng} / \mathrm{mL})$ & $1.3 \pm 0.8$ & $1.1 \pm 1.2$ & N.S. \\
Insulinogenic index & $0.72 \pm 0.77$ & $0.51 \pm 0.61$ & N.S. \\
$\Delta$ C-peptide $(\mathrm{ng} / \mathrm{mL})$ & $2.5 \pm 2.3$ & $1.2 \pm 1.4$ & $<0.0001$ \\
Disposition index $0-30$ & $1.6 \pm 1.9$ & $1.4 \pm 1.4$ & N.S. \\
Disposition index $0-120$ & $2.1 \pm 2.2$ & $1.7 \pm 1.5$ & N.S. \\
HOMA-IR & $1.2 \pm 0.6$ & $1.1 \pm 0.9$ & N.S. \\
Matsuda index & $8.7 \pm 11.7$ & $15.8 \pm 13.2$ & N.S. \\
\hline
\end{tabular}

HOMA-IR, homeostasis model assessment of insulin resistance. Data are means \pm SD. $p<0.05$ was taken to indicate significant difference. N.S. $=$ not significant.

Table 2 Correlation analyses between postoperative insulinogenic index, $\Delta$ C-peptide or disposition index and preoperative parameters

\begin{tabular}{|c|c|c|c|c|c|c|c|c|}
\hline & \multirow{2}{*}{\multicolumn{2}{|c|}{$\begin{array}{c}\text { Postoperative } \\
\text { insulinogenic index }\end{array}$}} & \multirow{2}{*}{\multicolumn{2}{|c|}{$\begin{array}{c}\text { Postoperative } \\
\Delta \text { C-peptide }(\mathrm{ng} / \mathrm{mL})\end{array}$}} & \multicolumn{4}{|c|}{ Postoperative disposition index } \\
\hline & & & & & \multicolumn{2}{|c|}{$0-30$} & \multicolumn{2}{|c|}{$0-120$} \\
\hline & $\mathrm{r}$ & $p$ & $\mathrm{r}$ & $p$ & $r$ & $p$ & $r$ & $p$ \\
\hline Age (years) & -0.17 & N.S. & -0.36 & 0.043 & -0.19 & N.S. & -0.23 & N.S. \\
\hline BMI $\left(\mathrm{kg} / \mathrm{m}^{2}\right)$ & -0.072 & N.S. & -0.021 & N.S. & -0.15 & N.S. & -0.16 & N.S. \\
\hline Pancreatic parenchymal thickness (mm) & 0.66 & $<0.0001$ & 0.65 & $<0.0001$ & 0.23 & N.S. & 0.31 & N.S. \\
\hline Fasting plasma glucose $(\mathrm{mg} / \mathrm{dL})$ & -0.32 & N.S. & -0.47 & 0.013 & -0.29 & N.S. & -0.38 & N.S. \\
\hline Fasting serum insulin $(\mu \mathrm{U} / \mathrm{mL})$ & 0.097 & N.S. & 0.066 & N.S. & 0.24 & N.S. & 0.20 & N.S. \\
\hline Fasting serum C-peptide (ng/mL) & 0.31 & N.S. & 0.66 & 0.0003 & -0.13 & N.S. & -0.070 & N.S. \\
\hline Preoperative insulinogenic index & 0.33 & N.S. & 0.027 & N.S. & 0.66 & 0.0005 & 0.64 & 0.0008 \\
\hline Preoperative $\Delta$ C-peptide (ng/mL) & 0.82 & $<0.0001$ & 0.91 & $<0.0001$ & 0.26 & N.S. & 0.42 & N.S. \\
\hline Preoperative disposition index $0-30$ & 0.058 & N.S. & 0.018 & N.S. & 0.013 & N.S. & 0.003 & N.S. \\
\hline Preoperative disposition index $0-120$ & 0.089 & N.S. & 0.012 & N.S. & 0.069 & N.S. & 0.076 & N.S. \\
\hline
\end{tabular}

$\mathrm{r}=$ correlation coefficient. N.S. $=$ not significant. $p<0.05$ was taken to indicate significant difference. 

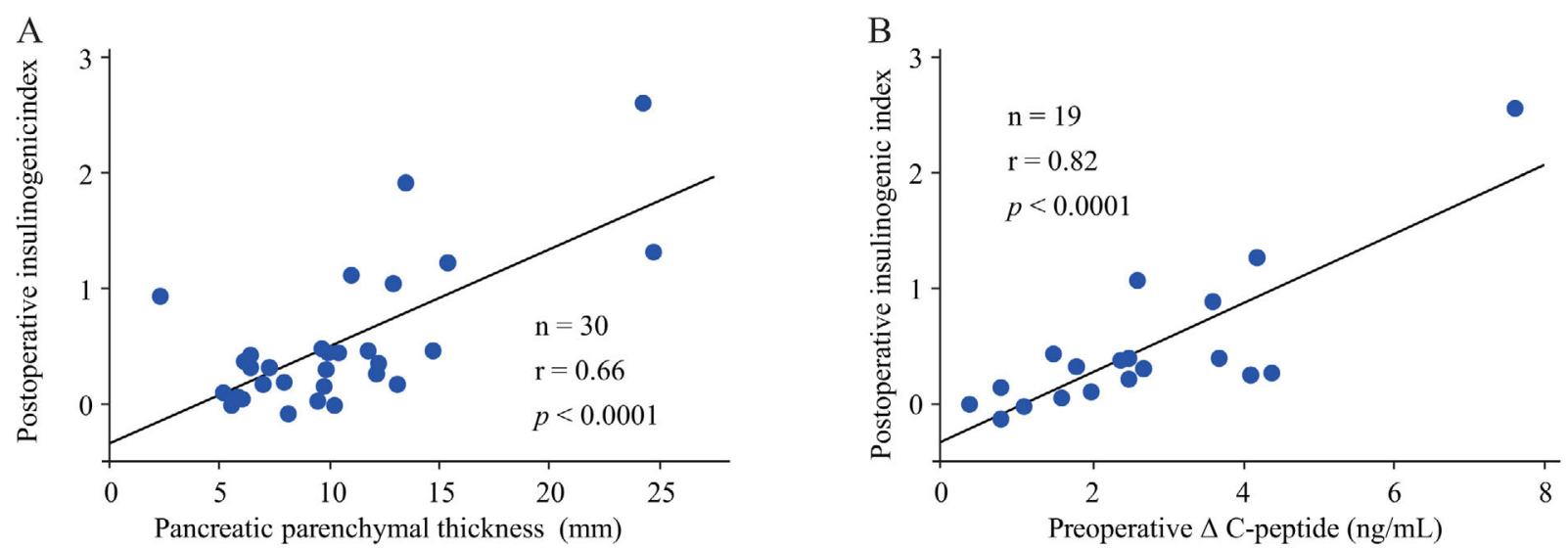

Fig. 2 The linear regression analyses between postoperative insulinogenic index and pancreatic parenchymal thickness (A) and preoperative $\Delta$ C-peptide (B). $\mathrm{r}=$ correlation coefficient. $p<0.05$ was taken to indicate a significant difference.

$=0.91, p<0.0001)$, pancreatic parenchymal thickness $(\mathrm{r}=0.65, p<0.0001)$, F-CPR $(\mathrm{r}=0.66, p=0.0003)$, FPG $(\mathrm{r}=-0.47, p=0.013)$ and age $(\mathrm{r}=-0.36, p=$ 0.043) (Fig. 3). A significant linear relationship was available between postoperative D.I. 0-30 and preoperative I.I. $(r=0.66, p=0.0005)$. A significant linear relationship was also available between postoperative D.I. 0-120 and preoperative I.I. $(\mathrm{r}=0.64, p=0.0008)$ (Fig. 4). Preoperative $\Delta \mathrm{C}$-peptide and pancreatic parenchymal thickness were associated with both postoperative I.I. and $\Delta$ C-peptide.

Multiple regression analysis including preoperative $\Delta \mathrm{C}$-peptide and pancreatic parenchymal thickness showed that preoperative $\Delta \mathrm{C}$-peptide was a significant determinant of postoperative I.I. (S.C. $=0.610, p$ $=0.0017)$. Pancreatic parenchymal thickness was not a significant determinant but was a reference predictor of postoperative I.I. (S.C. $=0.337, p=0.0541)$ (Table 3). Multiple regression analysis including preoperative $\Delta$ C-peptide, pancreatic parenchymal thickness, age and preoperative FPG showed that preoperative $\Delta$ C-peptide was the most significant determinant of postoperative $\Delta$ C-peptide (S.C. $=0.772, p<0.0001$ ), and pancreatic parenchymal thickness was the second (S.C. $=0.254$, $p=0.0178)$. Similarly, multiple regression analysis including preoperative F-CPR, pancreatic parenchymal thickness, age and preoperative FPG showed that preoperative F-CPR was the most significant determinant of postoperative $\Delta$ C-peptide (S.C. $=0.464, p=0.0021$ ), pancreatic parenchymal thickness was the second (S.C. $=0.373, p=0.0138$ ) and preoperative FPG was the third (S.C. $=-0.275, p=0.0412)($ Table 3$)$.
In the ROC curves, the best cut-off preoperative values for predicting the need for postoperative insulin therapy were a pancreatic parenchymal thickness of $6.0 \mathrm{~mm}$, a $\Delta$ C-peptide of $0.65 \mathrm{ng} / \mathrm{mL}$, a F-CPR of 0.85 $\mathrm{ng} / \mathrm{mL}$ and a FPG of $103.5 \mathrm{mg} / \mathrm{dL}$. All these parameters had high areas under the curve (AUCs), sensitivities, specificities, negative predictive values and positive likelihood ratios and low negative likelihood ratios. These parameters also had relatively low positive predictive values; $\Delta \mathrm{C}$-peptide had the highest positive predictive value, followed in descending order by pancreatic parenchymal thickness, F-CPR and FPG. Preoperative insulin therapy also had high specificity, a negative predictive value and a positive likelihood ratio, but it had relatively low sensitivity (Table 4).

We did not observe a significant relationship between postoperative plasma glucose levels in the 75-g OGTT $(0,30,60$ and $120 \mathrm{~min})$ and preoperative parameters (data not shown). The preoperative HOMA-IR was 1.2 \pm 0.6 , and the postoperative HOMA-IR was $1.1 \pm 0.9$. The preoperative Matsuda index was $8.7 \pm 11.7$, and the postoperative Matsuda index was $15.8 \pm 13.2$. There was no significant difference between these values (Table 1). However, the preoperative Matsuda index in patients whose glucose tolerance improved after surgery (borderline diabetic to normal, diabetic to normal or diabetic to borderline diabetic) increased more than in patients whose glucose tolerance did not improve (borderline diabetic to borderline diabetic, borderline diabetic to diabetic or diabetic to diabetic) $(5.6 \pm 2.4$ to $17.6 \pm 11.3$ vs. $6.2 \pm 3.7$ to $11.9 \pm 10.8)$. 
A

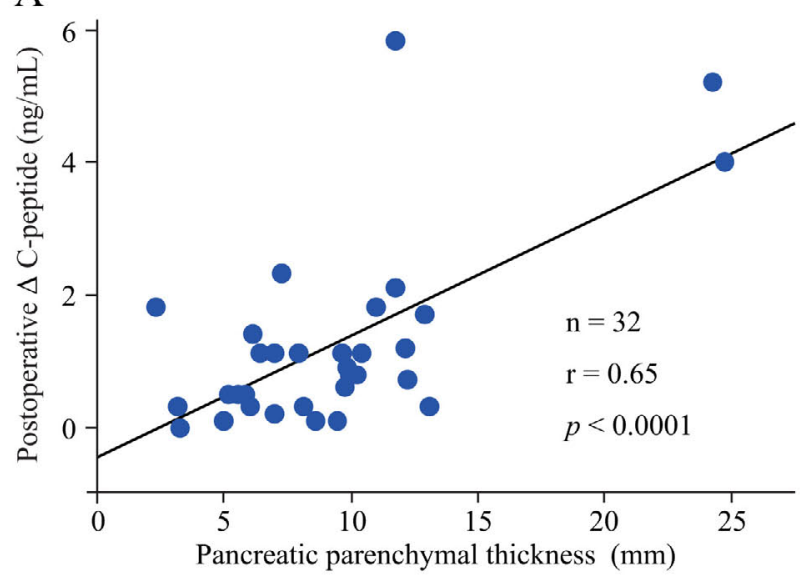

$\mathrm{C}$

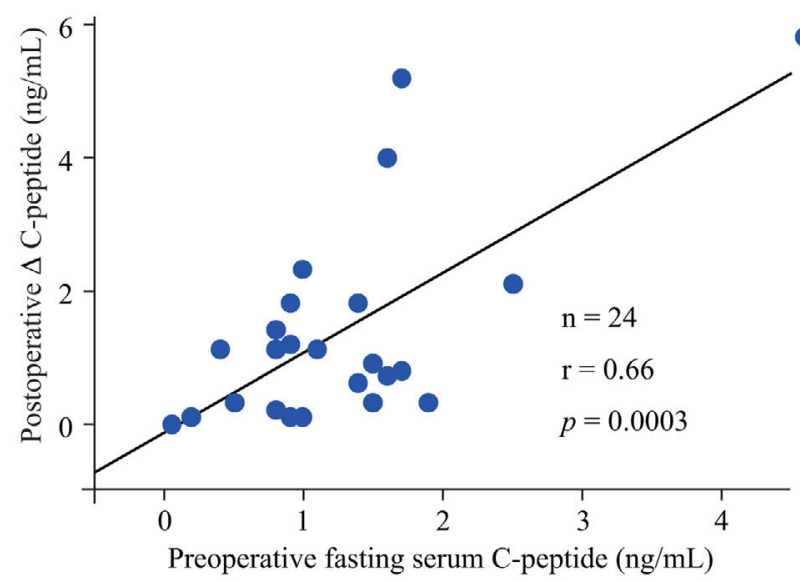

$\mathrm{B}$

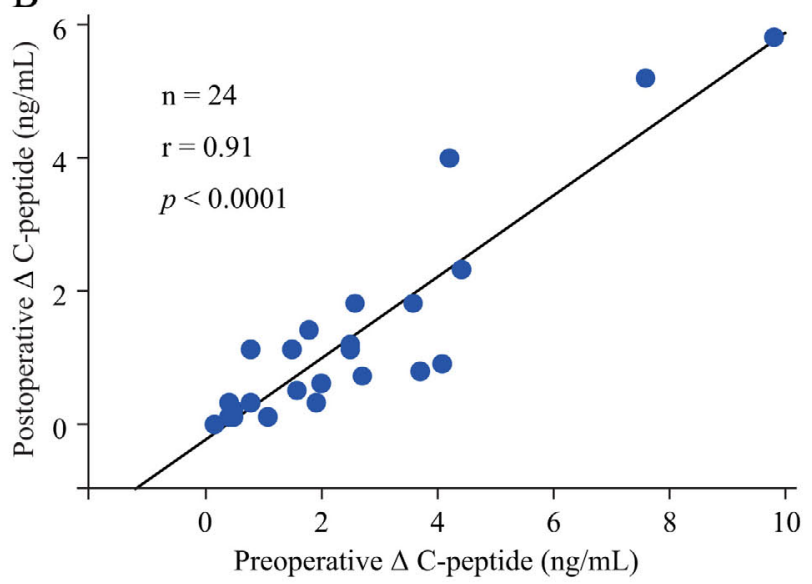

$\mathrm{D}$

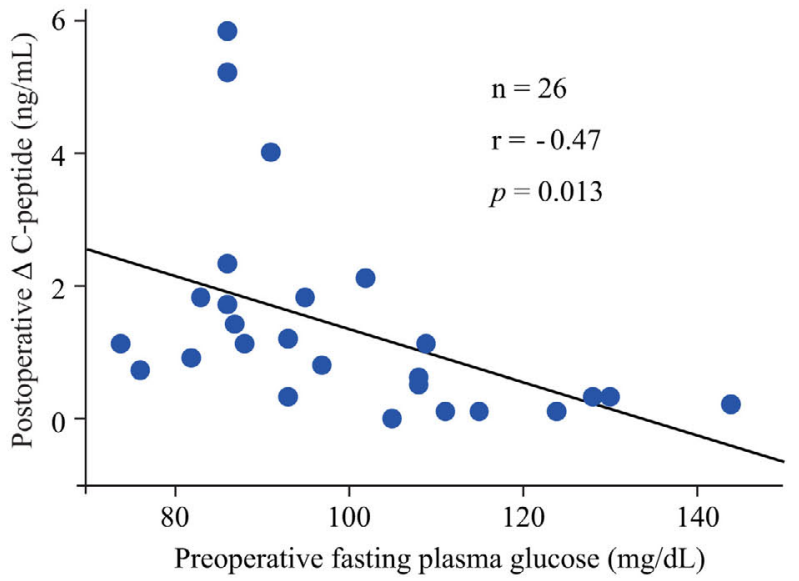

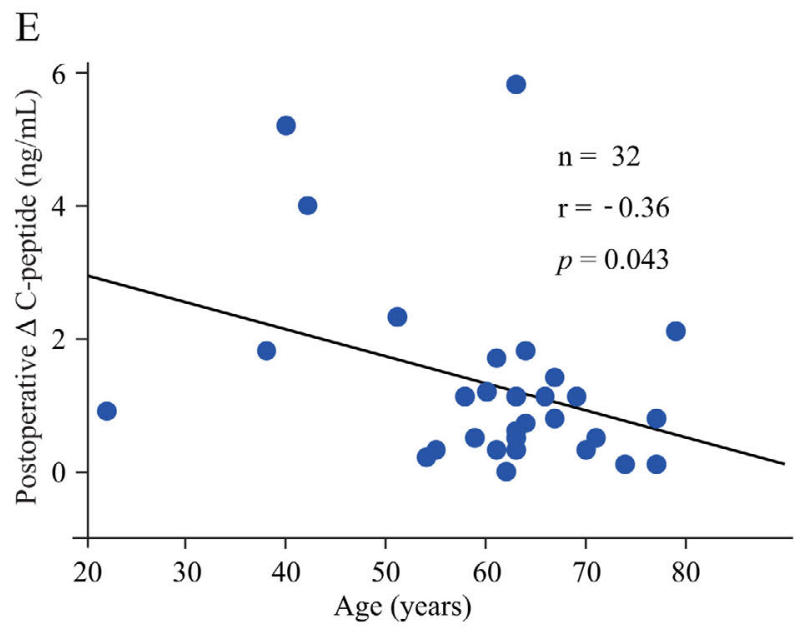

Fig. 3 The linear regression analyses between postoperative $\Delta$ C-peptide and pancreatic parenchymal thickness (A), preoperative $\Delta$ C-peptide (B), preoperative fasting serum C-peptide (C), preoperative fasting plasma glucose (D) and age (E). $r=$ correlation coefficient. $p<0.05$ was taken to indicate a significant difference. 
A

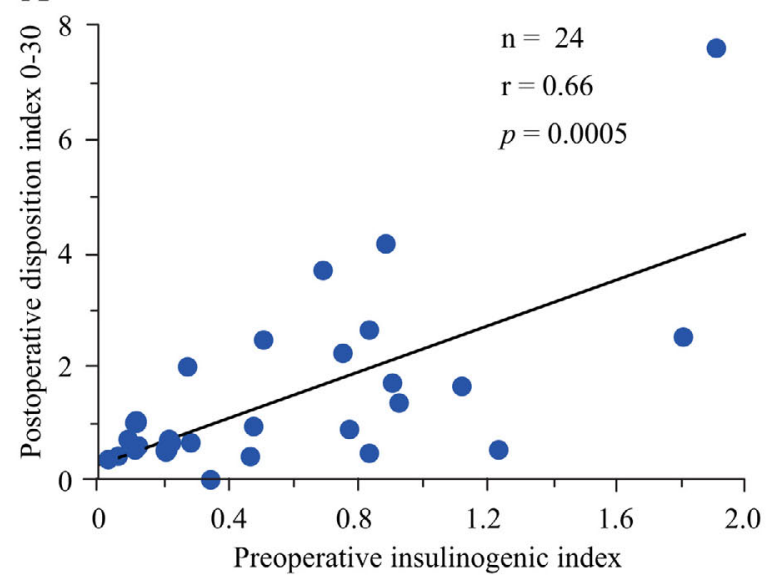

B

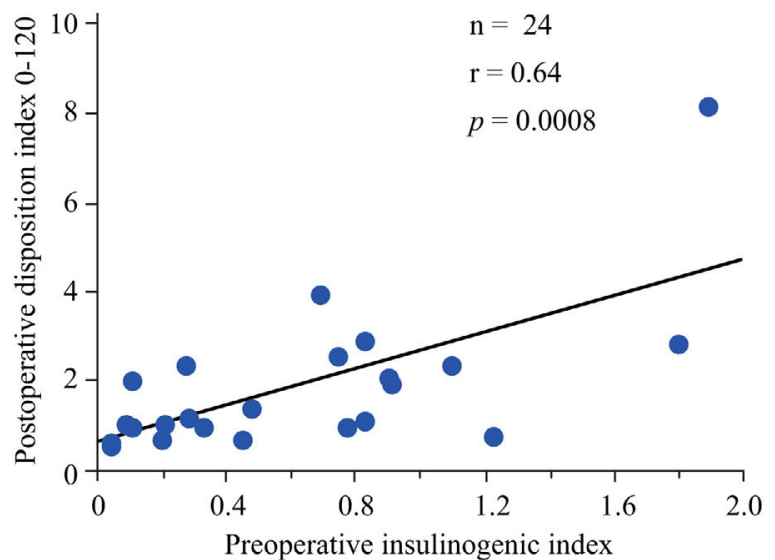

Fig. 4 The linear regression analysis between postoperative disposition index 0 -30 and preoperative insulinogenic index (A). The linear regression analysis between postoperative disposition index $0-120$ and preoperative insulinogenic index (B). $\mathrm{r}=$ correlation coefficient. $p<0.05$ was taken to indicate a significant difference.

Table 3 Multiple regression analysis of postoperative insulinogenic index and $\Delta \mathrm{C}$-peptide

\begin{tabular}{|c|c|c|c|c|c|}
\hline & \multicolumn{5}{|c|}{ Postoperative insulinogenic index } \\
\hline & Coefficient & S.E. & S.C. & $\mathrm{t}$ value & $p$ value \\
\hline Pancreatic parenchymal thickness (mm) & 0.037 & 0.018 & 0.337 & -2.801 & 0.0541 \\
\hline \multirow{3}{*}{ Preoperative $\Delta$ C-peptide $(\mathrm{ng} / \mathrm{mL})$} & 0.224 & 0.060 & 0.610 & 3.755 & 0.0017 \\
\hline & \multicolumn{5}{|c|}{ Postoperative $\Delta C$-peptide } \\
\hline & Coefficient & S.E. & S.C. & t value & $p$ value \\
\hline Preoperative $\Delta$ C-peptide $(\mathrm{ng} / \mathrm{mL})$ & 0.522 & 0.076 & 0.772 & 6.829 & $<0.0001$ \\
\hline Pancreatic parenchymal thickness (mm) & 0.073 & 0.028 & 0.254 & 2.595 & 0.0178 \\
\hline Age (years) & 0.001 & 0.010 & 0.005 & 0.055 & 0.9571 \\
\hline Preoperative fasting plasma glucose (mg/dL) & 0.0001425 & 0.008 & -0.002 & -0.017 & 0.9863 \\
\hline Preoperative serum C-peptide (ng/mL) & 0.844 & 0.237 & 0.464 & 3.563 & 0.0021 \\
\hline Pancreatic parenchymal thickness (mm) & 0.108 & 0.040 & 0.373 & 2.711 & 0.0138 \\
\hline Age (years) & -0.015 & 0.014 & -0.135 & -1.062 & 0.3014 \\
\hline Preoperative fasting plasma glucose (mg/dL) & -0.023 & 0.011 & -0.275 & -2.190 & 0.0412 \\
\hline
\end{tabular}

$p<0.05$ was taken to indicate significant difference. S.E., standard error; S.C., standard coefficient

Table 4 Characteristics of cut-off values of the preoperative clinical parameters for predicting the postoperative insulin requirement

\begin{tabular}{|c|c|c|c|c|c|c|c|c|}
\hline Parameters & $\begin{array}{c}\text { Optimal } \\
\text { cut-off value }\end{array}$ & AUC & $\begin{array}{l}\text { Sensitivity } \\
(\%)\end{array}$ & $\begin{array}{l}\text { Specificity } \\
(\%)\end{array}$ & $\begin{array}{l}\mathrm{PV}(+) \\
(\%)\end{array}$ & $\begin{array}{l}\text { PV(-) } \\
(\%)\end{array}$ & $\mathrm{LR}(+)$ & $\mathrm{LR}(-)$ \\
\hline$\Delta \mathrm{C}$-peptide (ng/mL) & 0.65 & 0.937 & 100 & 91 & 60 & 100 & 11.0 & 0 \\
\hline Fasting serum C-peptide (ng/mL) & 0.85 & 0.949 & 100 & 81 & 43 & 100 & 6.25 & 0 \\
\hline Fasting plasma glucose (mg/mL) & 103.5 & 0.910 & 100 & 77 & 30 & 100 & 3.9 & 0 \\
\hline \multirow[t]{3}{*}{ Parenchymal thickness (mm) } & 6 & 0.880 & 80 & 90 & 57 & 97 & 8.3 & 0.22 \\
\hline & 5 & & 40 & 94 & 50 & 91 & 6.2 & 0.64 \\
\hline & 7 & & 80 & 77 & 36 & 96 & 3.5 & 0.26 \\
\hline Preopearative insulin therapy & - & - & 60 & 97 & 75 & 94 & 18.6 & 0.41 \\
\hline
\end{tabular}

$\overline{\mathrm{AUC}}$, area under the ROC curve; $\mathrm{PV}(+)$, positive predictive value; $\mathrm{PV}(-)$, negative predictive value; LR $(+)$, positive likelihood ratio; $\mathrm{LR}(-)$, negative likelihood ratio. 


\section{Discussion}

Glucose intolerance is an important problem following PD. The attenuation of insulin secretion capacity resulting from reduced pancreatic volume is the main factor contributing to the worsening of glucose tolerance $[5,8]$. The present study is the first report in which preoperative parameters, including pancreatic parenchymal thickness, have been comprehensively examined for predicting postoperative insulin secretion and the need for postoperative insulin therapy in PD.

First, we showed that pancreatic parenchymal thickness, as well as other preoperative parameters including preoperative $\Delta \mathrm{C}$-peptide, F-CPR, I.I. and FPG, was significantly associated with postoperative insulin secretion. Multiple regression analyses revealed that the most significant determinant of postoperative $\Delta \mathrm{C}$-peptide was preoperative $\Delta \mathrm{C}$-peptide or F-CPR and that the most significant determinant of postoperative I.I. was preoperative $\Delta \mathrm{C}$-peptide. In these analyses, pancreatic parenchymal thickness was also a significant determinant of postoperative $\Delta \mathrm{C}$-peptide and a reference predictor of postoperative I.I. Second, we placed those parameters in order and determined the appropriate cut-off values for the need for postoperative insulin therapy by ROC analysis. Pancreatic parenchymal thickness, preoperative $\Delta \mathrm{C}$-peptide, preoperative F-CPR and preoperative FPG had high AUCs, sensitivities, specificities, negative predictive values and positive likelihood ratios and low negative likelihood ratios. Among the factors with positive predictive values, preoperative $\Delta \mathrm{C}$-peptide was the best for identifying subjects who needed postoperative insulin therapy, followed by pancreatic parenchymal thickness.

The present study revealed that preoperative insulin secretion could predict postoperative insulin secretion. However, the glucagon or glucose loading test is somewhat stressful and time-consuming [11]. Moreover, patients with malignant neoplasms of periampullary lesions are often fasting and under intravenous drip as a result of complications such as jaundice and pancreatitis [23]. In such patients, preoperative insulin secretion cannot be evaluated by $\Delta$ C-peptide, I.I., FPG or F-CPR. In our study, 11 patients could not undergo an intravenous glucagon test and 10 patients could not undergo a 75-g OGTT before surgery, 6 patients missed preoperative FPG and 8 patients missed preoperative F-CPR. In contrast, pancreatic parenchymal thickness could be measured without fail and would be less stressful and more convenient for these patients than $\Delta$ C-peptide and 75-g OGTT because a preoperative CT scan is routinely performed. The adequacy of measuring pancreas volume is also supported by a report that the pancreatic volume, as measured by CT with threedimensional imaging, predicts postoperative glucose intolerance 1 year after pancreatectomy [15]. In addition, 3 of 5 patients who needed postoperative insulin therapy had already been treated with insulin before surgery, suggesting that preoperative insulin therapy, as well as other preoperative parameters described above, can serve as a predictor of postoperative insulin need.

Preoperative parameters were able to predict postoperative insulin secretion but not postoperative glucose tolerance. A patient's need for postoperative insulin therapy for glycemic control could primarily be determined by postoperative insulin secretion capacity, but glucose tolerance might be also affected by postoperative factors other than insulin secretion, such as insulin resistance, the reconstruction procedure [24, 25] and incretin secretion $[6,26]$. In fact, glucose tolerance in 10 patients improved in spite of a decrease in insulin secretion in our study. This is consistent with previous observations in which glucose tolerance in approximately one-third or half of the patients with preoperative diabetes improved after surgery $[26,27]$. The Matsuda index in our patients with improved glucose tolerance increased more than in our patients without improved glucose tolerance, suggesting that amelioration of insulin resistance was one of the factors that improved postoperative glucose tolerance.

Based on the results obtained in this study, we would be able to select patients who need postoperative insulin therapy soon after PD. It is unclear whether the findings would improve the prognosis after PD in this study. In order to show the evidence that the findings would promise the better clinical course after PD, another prospective study would be needed.

In conclusion, pancreatic parenchymal thickness, preoperative $\Delta \mathrm{C}$-peptide, preoperative F-CPR, preoperative I.I. and preoperative FPG could predict postoperative insulin secretion. Among these parameters, preoperative $\Delta$ C-peptide, F-CPR or I.I. was the best parameter for predicting postoperative insulin secretion; however, pancreatic parenchymal thickness could also be a useful parameter in clinical practice. For patients undergoing $\mathrm{PD}$, a preoperative $\Delta \mathrm{C}$-peptide of $0.65 \mathrm{ng} / \mathrm{mL}$, a preoperative F-CPR of $0.85 \mathrm{ng} / \mathrm{mL}$, a pancreatic parenchymal thickness of $6.0 \mathrm{~mm}$ and a pre- 
operative FPG of $103.5 \mathrm{mg} / \mathrm{dL}$ might be optimal cutoff values for the requirement of insulin therapy for glycemic control after surgery.

\section{Acknowledgments}

We do not have any potential conflicts of interest relevant to this article.

\section{References}

1. Qiu D, Kurosawa M, Lin Y, Inaba Y, Matsuba T, Kikuchi S, Yagyu K, Motohashi Y, Tamakoshi A; JACC Study Group (2005) Overview of the epidemiology of pancreatic cancer focusing on the JACC Study. J Epidemiol 15: S157-S167.

2. Nakao A, Takagi H (1998) Problems in pancreatic cancer surgery. Semin Surg Oncol 15: 52-56.

3. Tran TC, van Lanschot JJ, Bruno MJ, van Ejick CH (2009) Functional changes after pancreatoduodenectomy: diagnosis and treatment. Pancreatology 9: 729737.

4. Stone WM, Sarr MG, Nagorney DM, Mcllrath DC (1988) Chronic pancreatitis. Results of Whipple's resection and total pancreatectomy. Arch Surg 123: 815-819.

5. Slezak LA, Andersen DK (2001) Pancreatic resection: effects on glucose metabolism. World J Surg 25: 452460.

6. Menge BA, Schrader H, Breuer TG, Dabrowski Y, Uhl W, Schmidt WE, Meier JJ (2009) Metabolic consequences of a $50 \%$ partial pancreatectomy in humans. Diabetologia 52: 306-317.

7. Kendall DM, Sutherland DE, Najarian JS, Goetz FC, Robertson RP (1990) Effects of hemipancreatectomy on insulin secretion and glucose tolerance in healthy humans. N Engl J Med 322: 898-903.

8. Miyata M, Takao T, Uozumi T, Okamoto E, Manabe H (1974) Insulin secretion after pancreatoduodenectomy. Ann Surg 179: 494-498.

9. Ritzel RA, Butler AE, Rizza RA, Veldhuis JD, Butler PC (2006) Relationship between beta-cell mass and fasting blood glucose concentration in humans. Diabetes Care 29: 717-718.

10. Butler AE, Janson J, Bonner-Weir S, Ritzel R, Rizza RA, Butler PC (2003) Beta-cell deficit and increased beta-cell apoptosis in humans with type 2 diabetes. Diabetes 52: 102-110.

11. Small M, Cohen HN, Beastall GH, MacCuish AC (1985) Comparison of oral glucose loading and intravenous glucagon injection as stimuli to C-peptide secretion in normal men. Diabet Med 2: 181-183.

12. Sakuma Y, Ricordi C, Miki A, Yamamoto T, Pileggi A, Khan A, Alejandro R, Inverardi L, Ichii H (2008) Factors that affect human islet isolation. Transplant Proc 40: 343-345.

13. Nano R, Clissi B, Melzi R, Calori G, Maffi P, Antonioli B, Marzorati S, Aldrighetti L, Freschi M, Grochowiecki
T, Socci C, Secchi A, Di Carlo V, Bonifacio E, Bertuzzi F (2005) Islet isolation for allotransplantation: variables associated with successful islet yield and graft function. Diabetologia 48: 906-912.

14. Matsumoto I, Sawada T, Nakano M, Sakai T, Liu B, Ansite JD, Zhang HJ, Kandaswamy R, Sutherland DE, Hering BJ (2004) Improvement in islet yield from obese donors for human islet transplants. Transplantation 78: 880-885.

15. Sakata N, Egawa S, Rikiyama T, Yoshimatsu G, Masuda K, Ohtsuka H, Ottomo S, Nakagawa K, Hayashi H, Morikawa T, Onogawa T, Yamamoto K, Yoshida H, Akada M, Motoi F, Naitoh T, Katayose Y, Unno M (2011) Computed tomography reflected endocrine function of the pancreas. J Gastrointest Surg 15: 525-532.

16. Philippe MF, Benabadji S, Barbot-Trystram L, Vadrot D, Boitard C, Larger E (2011) Pancreatic volume and endocrine and exocrine functions in patients with diabetes. Pancreas 40: 359-363.

17. Tomimaru Y, Takeda Y, Kobayashi S, Marubashi S, Lee CM, Tanemura M, Nagano H, Kitagawa T, Dono K, Umeshita K, Wakasa K, Monden M (2009) Comparison of postoperative morphological changes in remnant pancreas between pancreaticojejunostomy and pancreaticogastrostomy after pancreaticduodenectomy. Pancreas 38: 203-207.

18. Lemaire E, O'Toole D, Sauvanet A, Hammel P, Belghiti J, Ruszniewski P (2000) Functional and morphological changes in the pancreatic remnant following pancreaticoduodenectomy with pancreaticogastric anastomosis. Br J Surg 87: 434-438.

19. Kuzuya T, Nakagawa S, Satoh J, Kanazawa Y, Iwamoto Y, Kobayashi M, Nanjo K, Sasaki A, Seino Y, Ito C, Shima K, Nonaka K, Kadowaki T; Committee of the Japan Diabetes Society on the diagnostic criteria of diabetes mellitus (2002) Report of the committee on the classification and diagnostic criteria of diabetes mellitus. Diabetes Res Clin Pract 55: 65-85.

20. Bi Y, Zeng L, Zhu D, Yan J, Zhang Y, Tong G, Mu P, Shen S, Hu Y, Yu Q, Liang H, Weng J (2012) Association of $\beta$-cell function and insulin sensitivity with fasting and 2-h plasma glucose in a large Chinese population. Diabetes Obes Metab 14:174-180.

21. Madsbad S, Krarup T, McNair P, Christiansen C, Faber OK, Transbøl I, Binder C (1981) Practical clinical value of the C-peptide response to glucagon stimulation in 
the choice of treatment in diabetes mellitus. Acta Med Scand 210: 153-156.

22. DeFronzo RA, Matsuda M (2010) Reduced time points to calculate the composite index. Diabetes Care 33: e93.

23. Freelove R, Walling AD (2006) Pancreatic cancer: diagnosis and management. Am Fam Physician 73: 485492.

24. Yamaguchi K, Tanaka M, Chijiiwa K, Nagakawa T, Imamura M, Takada T (1999) Early and late complications of pylorus-preserving pancreatoduodenectomy in Japan 1998. J Hepatobilary Pancreat Surg 6: 303-311.
25. Jang JY, Kim SW, Park SJ, Park YH (2002) Comparison of the functional outcome after pylorus-preserving pancreatoduodenectomy: pancretogastrostomy and pancreatojejunostomy. World J Surg 26: 366-371.

26. Ohtsuka T, Kitahara K, Kohya N, Miyoshi A, Miyazaki K (2009) Improvement of glucose metabolism after a pancreatoduodenectomy. Pancreas 38: 700-705.

27. Pannala R, Leirness JB, Bamlet WR, Basu A, Petersen GM, Chari ST (2008) Prevalence and clinical profile of pancreatic cancer-associated diabetes mellitus. Gastroenterology 134: 981-987. 